\title{
CDISC SDTM Pharmacokinetic Parameter Long Name Terminology
}

National Cancer Institute

\section{Source}

National Cancer Institute. CDISC SDTM Pharmacokinetic Parameter Long Name

Terminology. NCI Thesaurus. Code C85493.

Terminology associated with the pharmacokinetic parameter test name codelist of the Clinical Data Interchange Standards Consortium (CDISC) Study Data Tabulation Model (SDTM). 